\title{
Major paternal depression and child consultation for developmental and behavioural problems
}

\author{
Shreya Davé, Lorraine Sherr, Rob Senior and Irwin Nazareth
}

\begin{abstract}
Background

It is well established that maternal depression is associated with enhanced child consultation for developmental and behaviour problems, but there is a dearth of research on paternal depression and child outcome.
\end{abstract}

Aim

To assess the association of major paternal depressed mood and child consultation for developmental and behaviour problems.

Design of study

Cross-sectional study.

Setting

General practices in London and Hertfordshire, UK.

Method

Fathers of children aged 4-6 years were recruited via 13 general practices. A sample of 248 biological father and mother dyads completed measures on depressive syndrome (Patient Health Questionnaire), child consultations with health professionals for developmental and behaviour problems, fathering, couple relationship quality, alcohol misuse, other psychiatric impairment, and sociodemographic factors. Results

Eight out of 248 fathers (3\%) had a major depressive syndrome. Sixty-five out of $247(26 \%)$ fathers reported they were responsible for taking their child to see the doctor at least half the time compared with mothers. Children of fathers with a major depressive syndrome were almost nine times more likely to have consulted a health professional for speech and language problems (adjusted odds ratio $[\mathrm{OR}]=8.67,95 \%$ confidence interval $[\mathrm{Cl}]=1.99$ to $37.67, P=0.004$ ) and seven times more likely to have consulted for externalising behaviour problems (adjusted $\mathrm{OR}=6.98,95 \% \mathrm{Cl}=$ 1.00 to $48.76, P=0.05$ ).

\section{Conclusion}

Children of fathers with major depression were more likely to consult for speech and language problems and externalising behaviour problems. A longitudinal study is recommended to identify causal mechanisms.

Keywords

child; child behaviour; child development; consultation; depression; paternal behaviour.

\section{INTRODUCTION}

The prevalence of depression among fathers of young children is notable. ${ }^{1}$ However, there has been little research on the specific effects of paternal depression on child outcome and consulting behaviour, with much of the existing literature being weighted in favour of maternal studies.

Maternal depression affects parenting and is associated with child developmental and behaviour problems. ${ }^{2}$ It is also associated with couple relationship discord ${ }^{3}$ and alcohol misuse, ${ }^{4,5}$ which also have an impact on a variety of child developmental outcomes. In addition to suffering a higher problem rate, children of mothers who are depressed are more likely to have an exaggerated consultation rate compared with those of mothers who are mentally well. ${ }^{6,7}$

Heightened parental concern can make referral for specialist care more likely, ${ }^{8}$ even if the child does not have a major problem. ${ }^{7}$ Mothers are more likely to take their child to see the doctor than fathers, and mothers suffering psychological distress are even

S Davé, BSc, MSc, epidemiologist, General Practice Research Framework, Medical Research Council, London. L Sherr, PhD, Dip Clin Psych, professor of health and clinical psychology, Primary Care and Population Sciences; $R$ Senior, MRCPsych, consultant child and adolescent psychiatrist, Leopold Muller Department of Child and Family Mental Health, University College London. I Nazareth, PhD, MRCGP, head of UCL Department of Primary Care and Population Health/director MRC General Practice Research Framework, London.

Address for correspondence

Ms Shreya Davé, General Practice Research Framework,

Medical Research Council, Stephenson House,

158-160 North Gower Street, London NW1 2ND.

E-mail: sd@gprf.mrc.ac.uk

Submitted: 12 March 2008; Editor's response: 21 July 2008; final acceptance: 21 October 2008.

@British Journal of General Practice.

This article was originally online first. Cite this article as: Br J Gen Pract 2009; 59: 180-185. Advance online publication. DOI: $10.3399 /$ bjgp09X407063 
more likely to take their child to see the doctor compared with mothers with no psychopathology. ${ }^{6}$ Mother-child consultation rates in young children aged 3-6 years were shown to be unrelated to mother-perceived severity of their 3-6-year-old children's health problems. ${ }^{6}$

In light of the established link between maternal depression and adverse child development and behaviour, and the dearth of comparable literature on children of fathers who are depressed, the main objective of this study was to evaluate whether major paternal depression was associated with child consultation with a health professional for developmental and behaviour problems.

\section{METHOD}

Families were recruited via 13 general practices in London and South East England. The computerised records of participating general practices were searched to identify children aged between 4 and 6 years. Children were linked to an adult household male who could be the father. ${ }^{1}$ The identified men were written to and sent a recruitment pack by their general practice. If there was no registered adult male at the household, the recruitment pack was addressed to the 'Father of $X$ ' (where $X$ was the child's name) and was posted to the child's address. The recruitment pack contained a consent form, eligibility form, and study questionnaire.

\section{Study eligibility}

Participants were biological fathers and mothers resident with the child. Competency in English was required to complete the study questionnaires. Children with major physical or mental problems (for example, Down's syndrome, cystic fibrosis, autism, or HIV) were excluded, as this could have an effect on both parental mood measurements and child consulting rates.

\section{Measures}

Box 1 summarises the measures completed by fathers and mothers including measures on depressive syndrome, child consultation for developmental and behavioural problems, and potential confounders. The potential confounders measured were those factors identified from the literature as being associated with both parental psychopathology and child outcome, and included variables on: fathering, couple relationship quality, parental alcohol misuse, maternal depression, other parental psychopathology, and sociodemographic factors.

\section{Data analysis}

Univariate analyses highlighted the:

\section{How this fits in}

There is a wealth of literature on the deleterious effects of maternal depression on child development, but little research on the effects of paternal depression on children. This study shows that children of fathers with major depression are more likely to consult their GP for externalising behaviour problems and speech and language problems, and are more likely to be referred for specialist care than children of fathers without major depression. Primary care is an ideal setting for further evaluation of this association, management, and the development of interventions.

- numbers of children that had consulted a GP or specialist health professional for speech and language problems, externalising problems, emotional symptoms, coordination problems, and eating problems; and

- prevalence of paternal Diagnostic and Statistical Manual of Mental Disorders (DSM-IV) ${ }^{9}$ major depressive syndrome, which was determined using the Patient Health Questionnaire ${ }^{10}$ depression scale.

The association between paternal responsibility for taking the child to the doctor and paternal major depressive syndrome was analysed using Fisher's exact test.

The crude associations between paternal major depressive syndrome and child consultation for speech and language problems, externalising problems, emotional symptoms, coordination problems, and eating problems were tested using logistic regression analysis. Potential confounders were identified by testing their associations $(P<0.10)$ with both paternal major depressive syndrome and child consultation for problems using $\chi^{2}$, Fisher's exact, and Wilcoxon rank sum tests.

Associations between paternal major depressive syndrome and consultation for child developmental and behavioural problems - including speech and language problems, externalising problems, emotional symptoms, coordination problems, and eating problems - that were significant in the crude analysis were further analysed using logistic regression analyses to test adjusted relationships. Modelling was aided using likelihood ratio tests; a cut-off of $P=0.05$ was used as the threshold for inclusion in the model.

\section{RESULTS}

The computerised records of the 13 participating GP practices identified 2269 eligible children aged between 4 and 6 years. A sample of 365 fathers who were eligible (that is, were resident biological fathers) and agreed to participate was obtained. In total, 250/365 (69\%) mothers consented. Full 
Box 1. Measures completed by fathers and mothers.

\begin{tabular}{|c|c|c|}
\hline Parameter (who completed) & Measure & Details \\
\hline \multicolumn{3}{|c|}{ Main outcome and explanatory variables } \\
\hline $\begin{array}{l}\text { Child consultation for developmental } \\
\text { and behavioural problems (M) }\end{array}$ & $\begin{array}{l}\text { Item list of child problems seen by a GP } \\
\text { or specialist, developed by authors }\end{array}$ & $\begin{array}{l}\text { Items included: hyperactivity, tantrums, and aggressive and } \\
\text { violent behaviour (categorised as 'externalising problems'); } \\
\text { withdrawn behaviour, poor concentration and sleeping } \\
\text { problems (categorised as 'emotional symptoms'); speech and } \\
\text { language problems; coordination problems; and eating problems }\end{array}$ \\
\hline Major depressive syndrome (F) & Patient Health Questionnaire ${ }^{10}$ & $\begin{array}{l}\text { Cross-sectional DSM-IV diagnosis for major } \\
\text { depressive syndrome }\end{array}$ \\
\hline \multicolumn{3}{|l|}{ Potential confounding variables } \\
\hline $\begin{array}{l}\text { Major depressive syndrome (M) } \\
\text { syndrome }\end{array}$ & Patient Health Questionnaire ${ }^{10}$ & Cross-sectional DSM-IV diagnosis for major depressive \\
\hline $\begin{array}{l}\text { Father responsibility for } \\
\text { taking child to doctor }(\mathrm{F})\end{array}$ & $\begin{array}{l}\text { Early Head Start Research and Evaluation } \\
\text { Project (NJ Cabrera, personal communication) }\end{array}$ & $\begin{array}{l}\text { Fathers indicated the extent to which they took their child } \\
\text { to see the doctor compared with their partner (at least half } \\
\text { the time versus less than half the time) }\end{array}$ \\
\hline Paternal role stress $(\mathrm{F})$ & $\begin{array}{l}\text { Early Head Start Research and Evaluation } \\
\text { Project Parental stress scale } \\
\text { (NJ Cabrera, personal communication) }\end{array}$ & $\begin{array}{l}\text { 14-item scale; a factor analysis was conducted and factors } \\
\text { were identified on paternal role stress, bonding with the } \\
\text { child, and perceptions of the child }\end{array}$ \\
\hline Father-child contact time (F) & Father diary developed by authors & $\begin{array}{l}\text { Fathers recorded number of waking hours spent with the child } \\
\text { on a typical weekday and a typical weekend day in the } \\
\text { previous week }\end{array}$ \\
\hline Attitudes towards parental role (F) & The Attitudes Towards Fathering Scale ${ }^{12}$ & $\begin{array}{l}\text { 36-item scale assessed whether fathers'attitudes toward the } \\
\text { paternal role were more 'traditional' or 'developmental' in nature }\end{array}$ \\
\hline Other psychiatric impairment $(\mathrm{F}, \mathrm{M})$ & Patient Health Questionnaire ${ }^{10}$ & $\begin{array}{l}\text { Cross-sectional DSM-IV diagnosis for panic syndrome, } \\
\text { other anxiety syndrome, and somatoform disorder }\end{array}$ \\
\hline Couple relationship quality $(\mathrm{F}, \mathrm{M})$ & The Dyadic Adjustment Scale ${ }^{13}$ & $\begin{array}{l}\text { Standardised } 32-\text { item scale assessed: dyadic consensus, } \\
\text { dyadic satisfaction, affectional expression, and dyadic cohesion }\end{array}$ \\
\hline Alcohol misuse (F, M) & $\begin{array}{l}\text { WHO Alcohol Use Disorders Identification } \\
\text { Test (AUDIT questionnaire) }{ }^{14}\end{array}$ & $\begin{array}{l}\text { Assessed alcohol consumption in the past year using a } 10 \text {-item } \\
\text { scale. Score of eight and above indicates risk of hazardous } \\
\text { alcohol intake }\end{array}$ \\
\hline Sociodemographic factors (F, M) & UK census measures ${ }^{15}$ & $\begin{array}{l}\text { Age, marital status, employment status, housing tenure, car/van } \\
\text { ownership, education /qualifications, and ethnicity }\end{array}$ \\
\hline
\end{tabular}

AUDIT $=$ Alcohol Use Disorders Identification Test, DSM = Diagnostic and Statistical Manual of Mental Disorders ${ }^{9} \mathrm{~F}=$ fathers, $M=$ mothers, WHO $=$ World Health Organization.

couple-completed data were available for 248 father and mother dyads. The data analysis was based on this group.

The full demographic profile of the sample has been reported in a previous article. ${ }^{16}$ The sample of participating fathers was predominantly white and middle class.

Fifty of the 248 children had consulted a health professional for a total of 66 problems of the kind described above since they were 2 years of age. Forty-one of the 248 children (17\%) had consulted for one problem; six $(2 \%)$ had consulted for two problems, and three (1\%) had consulted for three or more problems. The most common problem consulted for was speech and language problems (36/248, 15\% children). Fifty-six of the $66(85 \%)$ problems were referred to a specialist health professional (for example, a paediatrician, a speech and language therapist, and a psychologist) (Table 1).

Eight of the 248 (3\%) fathers had a major depressive syndrome.

\section{Paternal responsibility for taking the child to the doctor}

Sixty-five out of 247 (26\%) fathers reported that they took their child to see the doctor at least half the time compared with mothers. No fathers who were depressed reported this but there was no significant difference in self-reported paternal responsibility for taking the child to the doctor (at least half the time compared with mothers) by paternal depression status; $0 / 8(0 \%)$ and 65/239 (27\%) among fathers with and without a major paternal depressive syndrome respectively, Fisher's exact $=0.12$. 
Paternal depression and child consultation for developmental or behavioural problems

Logistic regression analyses. Table 2 shows that paternal major depressive syndrome was associated with almost a seven times higher likelihood of consultation for speech and language problems compared with fathers without a major depressive syndrome. After controlling for father responsibility for taking the child to the doctor, a paternal major depressive syndrome was associated with almost a nine times greater likelihood that the child had consulted for a speech and language problem compared with fathers without a major depressive syndrome. Fathers who took responsibility for taking their child to the doctor at least half the time were more than twice as likely to have a child with a speech and language problem compared with fathers who took their child to see the doctor less than half the time (Table 2).

Fathers with a major depressive syndrome were 11 times more likely to have a child who had consulted for an externalising problem than fathers without a major depressive syndrome. After adjusting for being a home owner, fathers were almost seven times more likely to have a child who had consulted for hyperactivity than fathers without a major depressive syndrome. Being a home owner was associated with an $88 \%$ lower likelihood of child consultation for externalising problems compared with fathers who were not home owners.

Fathers who had a major depressive syndrome were almost 16 times more likely to have a child who had consulted for an eating problem compared with fathers without a major depressive syndrome, however after controlling for paternal role stress this relationship was of borderline significance.
Table 1. Child consultation for developmental or behavioural problems since 2 years of age.

\begin{tabular}{|c|c|c|c|}
\hline Problem consulted for & $\begin{array}{l}\text { Seen GP only } \\
\qquad(n=248)\end{array}$ & $\begin{array}{c}\text { Referred to see specialist } \\
\text { health professional }(n=248)\end{array}$ & $\begin{array}{c}\text { Total } \\
(n=248)\end{array}$ \\
\hline Speech and language problems & 2 & 34 & 36 \\
\hline Externalising problems & 2 & 7 & 9 \\
\hline Emotional symptoms & 1 & 6 & 7 \\
\hline Coordination problems & 2 & 5 & 7 \\
\hline Eating problems & 3 & 4 & 7 \\
\hline Total & 10 & 56 & 66 \\
\hline
\end{tabular}

Increasing paternal role stress was associated with a $17 \%$ higher chance of child consultation for eating problems.

No significant associations were found between a paternal major depressive syndrome and child emotional symptoms or child coordination problems.

\section{DISCUSSION}

\section{Summary of main findings}

This study investigated the relationship between a DSM-IV ${ }^{9}$ major depressive syndrome among fathers of 4-6 year olds and child consultation with health professionals for developmental or behavioural problems since the age of 2 years. Children of fathers with a paternal major depressive syndrome were almost nine times more likely to have consulted a health professional for speech and language problems and seven times more likely to have consulted a health professional for externalising behaviour problems.

\section{Strengths and limitations of the study}

This study benefitted from utilisation of the Patient Health Questionnaire, which indicated the presence Table 2. Logistic regression models for paternal major depressive syndrome and
child consultation for developmental and behavioural problems.

\begin{tabular}{|c|c|c|c|c|}
\hline Factor & $\begin{array}{l}\text { Crude odds } \\
\text { ratio }(95 \% \mathrm{Cl})\end{array}$ & $P$-value & $\begin{array}{l}\text { Adjusted odds } \\
\text { ratio }(95 \% \mathrm{Cl})\end{array}$ & $P$-value \\
\hline \multicolumn{5}{|l|}{ Speech and language problems $(n=247)$} \\
\hline Paternal major depressive syndrome (yes) & 6.47 (1.54 to 27.17$)$ & 0.011 & 8.67 (1.99 to 37.67$)$ & 0.004 \\
\hline Father takes child to doctor at least half the time (yes) & $-\quad-$ & & $2.38(1.11$ to 5.12$)$ & 0.027 \\
\hline \multicolumn{5}{|l|}{ Externalising problems $(n=247)$} \\
\hline Paternal major depressive syndrome (yes) & 11.05 (1.89 to 64.74$)$ & 0.008 & $6.98(1.00$ to 48.76$)$ & 0.050 \\
\hline Home owner (yes) & - & & $0.12(0.03$ to 0.50$)$ & 0.004 \\
\hline \multicolumn{5}{|l|}{ Eating problems $(n=248)$} \\
\hline Paternal major depressive syndrome (yes) & 15.67 (2.52 to 97.57$)$ & 0.003 & $6.38(0.74$ to 54.74$)$ & 0.091 \\
\hline Paternal role stress (score) & - & & $1.17(1.00$ to 1.37$)$ & 0.054 \\
\hline \multicolumn{5}{|l|}{ Emotional symptoms $(n=248)$} \\
\hline Paternal major depressive syndrome (yes) & $5.57(0.59$ to 52.68$)$ & 0.130 & - & - \\
\hline \multicolumn{5}{|l|}{ Coordination problems $(n=248)$} \\
\hline Paternal major depressive syndrome (yes) & 5.57 (0.59 to 52.68$)$ & 0.130 & - & - \\
\hline
\end{tabular}


of a major depressive syndrome. Data were collected on key potential confounders of the association of paternal depressed mood and child outcome including other parental psychopathologies, couple relationship quality, alcohol use, and sociodemographic variables. Study participants were recruited from a diverse range of practices in South East England, providing a population that was socioeconomically and ethnically diverse.

However, despite the socioeconomic diversity of the practice areas, the study sample was predominantly white and middle class ${ }^{16}$ and, therefore, the results cannot be generalised to other populations. In addition, as this study was crosssectional, causality could not be determined.

The study measured paternal depressive syndrome over the previous 2 weeks; however, the outcome measures were child consultations for problems since they were aged 2 years. The lack of synchronicity between the outcome and explanatory measures may have diluted any potential effects of paternal depressed mood on child outcome, or child consultation may have predated the paternal depressive syndrome. A longitudinal study would allow the elucidation of the direct effects of paternal depressed mood on child consultation for problems both concurrently and longitudinally where paternal depressed mood would predate consultation for the child problems.

This study relied on mothers' reports of child consultation; future studies would benefit from validation of child problems from the children's medical records.

The study was also limited by a small sample size and, therefore, low rates of paternal major depressive syndrome and some child problems. Although the response rate was low $(16 \%$ at the strictest definition), it was not known what proportion of non-responders were ineligible to participate. The response rate is likely to be higher if estimates of non-availability of a biological father in the home, non-delivery of questionnaires, and non-English-speaking participants were known. Future studies on paternal depression and child development should be powered on the rarer child outcomes of interest in order to gain an adequate sample size to detect group differences.

\section{Comparison with existing literature}

The observed associations could represent a presence of higher levels of speech and language problems and externalising problems among children of fathers who are depressed.

There is a wealth of literature on the adverse effects of maternal depression on child development and behaviour. ${ }^{2,17}$ Maternal depression can affect child outcome through impaired parenting, as mothers who are depressed are typically hostile and less communicative with their children than those who are not depressed. ${ }^{18-21}$ McCarty et al found that the effect of maternal depression on disruptive (externalising) behaviour disorders in their children was mediated by a difficult mother-child relationship. ${ }^{22}$ Covariates of parental depression, such as couple relationship discord $^{3}$ and parental alcohol misuse, ${ }^{5}$ can also affect child development and behaviour.

The study findings could also represent higher consultation rates by children of fathers who are depressed, regardless of whether or not the child has an actual problem. Maternal depression, ${ }^{6}$ anxiety, ${ }^{23}$ and somatoform symptoms ${ }^{6}$ are associated with higher child consultation rates. Higher child consultation for problems could be an artefact of a 'depression distortion bias' where mothers who are depressed have a more negative perception of their children and are likely to overreport child problems compared with mothers who do not have depression. ${ }^{2,24,25}$ However, it has also been suggested that mothers who are depressed are more sensitive to problems in their children than those who are not. ${ }^{26}$

In this study, maternal psychopathology was tested as a confounder, as mothers are more often responsible for the decision to take their child to the doctor than fathers. ${ }^{27}$ Confounding by comorbid paternal psychopathologies such as paternal somatoform disorder and panic syndrome was also tested for. Neither maternal psychopathology (including maternal depression) nor comorbid paternal psychopathology confounded the relationship between paternal major depressive syndrome and consultation for child speech and language or externalising problems; this suggests that the increased child consultation rates associated with paternal depression may be for genuine problems. An alternative interpretation of these findings is that child problems may have caused parental psychopathology. ${ }^{18,28} \mathrm{~A}$ child with developmental or behaviour problems can generate a stressful familial environment. It is important for health services to provide adequate support to families presenting with either parental psychopathology or child adjustment problems.

\section{Implications for future research and practice}

The following theories may explain the observed findings either solely or in combination:

- major depression in fathers may cause child 
developmental and behavioural problems either directly through impaired parenting behaviour or via covariates of depression such as couple relationship discord and alcohol misuse;

- higher consultation rates among children of fathers who are depressed may be due to parental anxiety and a negative perception of the child or a lower threshold for acceptance of the child's development and behaviour rather than genuine child problems; and

- children with developmental and behaviour problems may cause psychopathology in their parents either directly through difficult-to-manage behaviour or through other mechanisms, for instance, couple relationship discord, which may be prevalent among families with a problem child.

A longitudinal study is recommended to examine these hypotheses and identify causal mechanisms, differentiate between long-term and recent depression, and understand maternal and paternal components. Parameters evaluating the child consultation decision-making processes within families should be assessed to make comparisons between families with fathers and/or mothers with psychopathology and families with no parental mental illness.

Children presenting in primary care with speech and language problems or externalising problems should be assessed in the context of their parents' mental health, with a specific focus on the father.

\section{Funding body}

This study was funded by the Royal College of General Practitioners (SFB 2004/02) and the North Central London Research Consortium (NoCLoR)

\section{Ethical approval}

This study was reviewed and approved by Camden and Islington Local Research Ethics Committee (02/146), Brent Medical Ethics Committee (BEC 980), Harrow Research Ethics Committee (3134), and Hertfordshire Local Research Ethics Committee (ECO3629)

\section{Competing interests}

The authors have stated that there are none

\section{Acknowledgements}

We would like to thank the families involved and the general practices for their participation in the study.

\section{Discuss this article}

Contribute and read comments about this article on the Discussion Forum: http://www.rcgp.org.uk/bjgp-discuss

\section{REFERENCES}

1. Sherr L, Davé S, Lucas P, et al. A feasibility study on recruiting fathers of young children to examine the impact of paternal depression on child development. Child Psychiatry Hum Dev 2006; 36(3): 295-309.

2. Murray L, Cooper P, (eds). Postpartum depression and child development. New York: Guilford Press, 1997.

3. Downey G, Coyne JC. Children of depressed parents: an integrative review. Psychol Bull 1990; 108(1): 50-76.

4. El-Sheikh M, Flanagan E. Parental problem drinking and children's adjustment: family conflict and parental depression as mediators and moderators of risk. J Abnorm Child Psychol 2001; 29(5): 417-432.

5. Steinhausen HC. Children of alcoholic parents. A review. Eur Child
Adolesc Psychiatry 1995; 4(3): 143-152.

6. Leach J, Ridsdale L, Smeeton N. Is there a relationship between a mother's mental state and consulting the doctor by the family? A study in a military general practice. Fam Pract 1993; 10(3): 305-311.

7. Levy RL, Langer SL, Walker LS, et al. Relationship between the decision to take a child to the clinic for abdominal pain and maternal psychological distress. Arch Pediatr Adolesc Med 2006; 160(9): 961-965.

8. Lynch TR, Wildman BG, Smucker WD. Parental disclosure of child psychosocial concerns: relationship to physician identification and management. J Fam Pract 1997; 44(3): 273-280.

9. American Psychiatric Association. Diagnostic and Statistical Manual of Mental Disorders. Washington DC: American Psychiatric Association, 2000.

10. Spitzer RL, Kroenke K, Williams JB. Validation and utility of a selfreport version of PRIME-MD: the PHQ primary care study. Primary care evaluation of mental disorders. Patient Health Questionnaire. JAMA 1999; 282(18): 1737-1744.

11. Tamis-LeMonda CS, Shannon JD, Cabrera NJ, Lamb ME. Fathers and mothers at play with their 2- and 3-year-olds: contributions to language and cognitive development. Child Dev 2004; 75(6): 1806-1820.

12. Bigner JJ. Attitudes toward fathering and father-child activity. Home Economics Research Journal 1977; 6: 98-106.

13. Spanier GB. Measuring dyadic adjustment: New scales for assessing the quality of marriage and similar dyads. J Marriage Fam 1976; 38: $15-28$.

14. Barbor TF, de la Fuente JR, Saunders J, et al. The alcohol use disorders identification test: guidelines for the use in primary health care. Geneva: World Health Organization, 1989.

15. Office for National Statistics. Census 2001. CD supplement to the National report for England and Wales and key statistics for local authorities in England and Wales. London: ONS, 2003.

16. Davé S, Sherr L, Senior R, et al. Associations between paternal depression and behaviour problems in children of 4-6 years. Eur Child Adolesc Psychiatry 2008; 17(5): 306-315.

17. Cummings EM, Davies PT. Maternal depression and child development. J Child Psychol Psychiatry 1994; 35(1): 73-112.

18. Edhborg M, Lundh W, Seimyr L, Widström AM. The parent-child relationship in the context of maternal depressive mood. Arch Womens Ment Health 2003; 6(3): 211-216.

19. Elgar FJ, Mills RS, McGrath PJ, et al. Maternal and paternal depressive symptoms and child maladjustment: the mediating role of parental behavior. J Abnorm Child Psychol 2007; 35(6): 943-955.

20. Lovejoy MC, Graczyk PA, O'Hare E, Neuman G. Maternal depression and parenting behavior: a meta-analytic review. Clin Psychol Rev 2000; 20(5): 561-592.

21. Murray L, Fiori-Cowley A, Hooper R, Cooper P. The impact of postnatal depression and associated adversity on early mother-infant interactions and later infant outcome. Child Dev 1996; 67(5): 2512-2526.

22. McCarty CA, McMahon RJ, Conduct Problems Preventions Research Group. Mediators of the relation between maternal depressive symptoms and child internalizing and disruptive behavior disorders. J Fam Psychol 2003; 17(4): 545-556.

23. Campion PD, Gabriel J. Illness behaviour in mothers with young children. Soc Sci Med 1985; 20(4): 325-330.

24. Chilcoat HD, Breslau N. Does psychiatric history bias mothers' reports? An application of a new analytic approach. J Am Acad Child Adolesc Psychiatry 1997; 36(7): 971-979.

25. Najman JM, Williams GM, Nikles J, et al. Mothers' mental illness and child behavior problems: cause-effect association or observation bias? J Am Acad Child Adolesc Psychiatry 2000; 39(5): 592-602.

26. Ackermann R, DeRubeis RJ. Is depressive realism real? Clin Psychol Rev 1991; 11: 565-584.

27. Field S, Draper J, Hare MJ. Babies' illness from a parents' point of view. Maternal Child Health 1983; 8: 252-256.

28. Baker BL, Heller TL. Preschool children with externalizing behaviors: experience of fathers and mothers. J Abnorm Child Psychol 1996; 24(4): 513-532. 